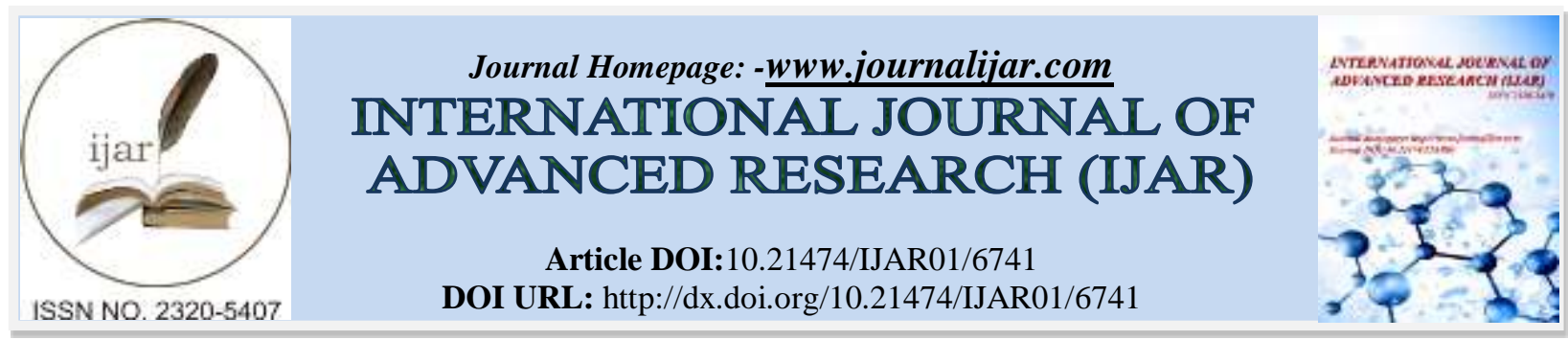

RESEARCH ARTICLE

\title{
MATHEMATICAL COMMUNICATION PROCESS OF JUNIOR HIGH SCHOOL STUDENTS BASED ON KEIRSEY PERSONALITY TYPE IN SOLVING OPEN GEOMETRY PROBLEMS
}

\author{
Vinny Dwi Librianti ${ }^{1}$, Sunardi ${ }^{2}$ and Slamin ${ }^{3}$. \\ 1. Master student in the Department of Mathematics Education, University of Jember, Kalimantan Street 37, \\ Jember 68121, Indonesia. \\ 2. Department of Mathematics Education, University of Jember, Kalimantan Street 37, Jember 68121, Indonesia. \\ 3. Department of Mathematics Education, University of Jember, Kalimantan Street 37, Jember 68121, Indonesia.
}

\section{Manuscript Info}

Manuscript History

Received: 13 January 2018

Final Accepted: 15 February 2018

Published: March 2018

Keywords:-

Mathematical Communication,

Personality Type, Problem Solving,

Geometry.

\section{Abstract}

The aim of this research is to describe the students' mathematical communication process of guardian, artist, rational, and idealist personality type in solving the geometry open problems. This research is a descriptive research with qualitative approach with data collection using questionnaire, test, and interview method. Data analysis uses descriptive analysis. The results reveal that each personality type is different in showing the process of mathematical communication. Guardian students show more symbolic communication, then logical, and verbal communication. Artist students show more verbal communication, then symbolic, and logical communication. Rational students show logical, symbolic, and verbal communication at every stage of problem resolution. While idealistic students, they show more logical and verbal communication, then symbolic communication.

Copy Right, IJAR, 2018,. All rights reserved.

\section{Introduction:-}

Mathematics is one type of languages that symbolizes a set of meaningful statements to be conveyed. Someone can improve his mathematical conceptual understanding by expressing his mathematical ideas to others (Huggins in Qohar, 2011). The Literacy and Numeracy Secretariat (2010) suggests that mathematical communication is an essential process in learning mathematics. Students can reflect, clarify, and broaden their ideas in understanding relationships and mathematical arguments through communication.

Students with good mathematical communication skill will find it easier to find alternative solutions to problems because students can make diverse representations of the problem. However, in fact, students sometimes are able to solve math problems well, but they do not understand the true meaning of what is being done. In Armiati's (2009) study, students are less able to communicate well, as if something which they think is only for themselves. Based on preliminary study conducted related to the mathematical communication ability of students in junior high school level, it was obtained the result that is in solving a problem students do not write down information that is known and asked on the matter. Students directly represent the sentence matter into the image form. Students can use rules or formulas correctly and understand the symbols used. However, the number of counting operations performed is not correct. The conclusion of the answer made is also not correct because it is based on the wrong calculation and the students do not understand the drawings that have been made. Students' mathematical communication is very 
important because it can help teachers to understand the ability of students in interpreting and expressing their understanding of the concept and process of the problem solving.

Open-solving problems is a problem-solving by using many alternative ways of completion and having one answer or having the right answer (Herman, 2007). Open-solving problems will further train students to communicate their ideas appropriately through verbal representations as well as representations in the form of drawings, diagrams, graphs, and symbols. In this research, we will see the process of students' mathematical communication based on the standard of communication process by NCTM (2000) that is how students can express the mathematical ideas orally, written, or visual drawing clearly and logically which is called logical communication, how students interpret and evaluate mathematical ideas both verbally and in writing which is called verbal communication, and how students use terms, symbols, and structures to model a mathematical situation or problem which is called symbolic communication. From the open problems given, solved by Polya step, that is understand the problem, make plan, execute plan, and recheck. While the material chosen to express the process of students' mathematical communication in solving problems is geometry. The uniqueness of geometry compared with other fields in mathematics is that geometry has the abstraction of objects that require students to be able to imagine things that are not clear or not real in their physical form. The students' mathematical communication in the field of geometry will be more interesting. Students will convey more ideas or mathematical messages from their visual and spatial experiences, such as fields, patterns, measurements, and mapping. Geometry also provides approaches, for example with drawings, diagrams, coordinate systems, vectors, and transformations in problem solving.

According to Jung, (in Keirsey, 1998) the way a person accepts, processes, and conveys information to others is different because it is influenced by his inner personality. Bents (2010) reveals that communication is a way of expressing opinions and decisions on a matter where the communication of each person is different due to differences in personality. There are 4 personality types classified by a psychologist, David Keirsey. They are guardian, artist, rational, and idealist. Dewiyani (2010) finds that there are differences between the four personality types, for example in understanding the problem. The guardian, artist, rational, and idealist students begin in the order of sentences on the matter. However, then the guardian students take the meaning of the sentence and mark the part that he thinks is important. Artist students take the sentence core and do more body movements. The rational students take the essence of the sentence and then make the symbol. While the idealist students take the sentence core, and like to move the pen. There is a point that greatly distinguishes rational and artist types, that is in accepting information, rational type will do so by intuition while the type of artist is based on the five senses or something that can be felt directly. Teachers should not directly provide a variable at the start of teaching artist type students, but they can be started from applying on real life. Giving variables at the start of the learning can be done for rational type students. Based on the above description, it is necessary to conduct a study entitled "Mathematical Communication Process of Junior High School Students Based on Keirsey Personality Type in Solving Open Geometry Problems".

\section{Research Method:-}

The type of this research is a descriptive research with qualitative approach. There are four students selected as research subjects. They are from each guardian, artist, rational, and idealist personality type in VIII-A class of Junior high School 2 Jember. In this study, researchers in addition to act as a research manager also becomes as the main instrument in collecting data. Supporting instruments are a questionnaire of Keirsey's personality type, open-solving problems, and interview guidelines.

The research was done by giving questionnaires of the personality type classification to all students of a class which is useful for knowing the student's personality. Questionnaire contains of 16 statements and each statement contains alternative answers; a, b, c, and d. Then, it determined one student of each personality type as the subject of the study. After providing a personality type questionnaire, the next step is to provide an open-solving problem test to four specified students. Both the questionnaire and the open-solving problems test have been validated by two lecturers of S1 and one lecturer of S2 at Mathematics Education of Jember University. The final step is an interview aimed at ensuring the student's writing and reinforcing the findings obtained, as well as for obtaining deeper analysis. The problems given to the subject of research are as follows: 


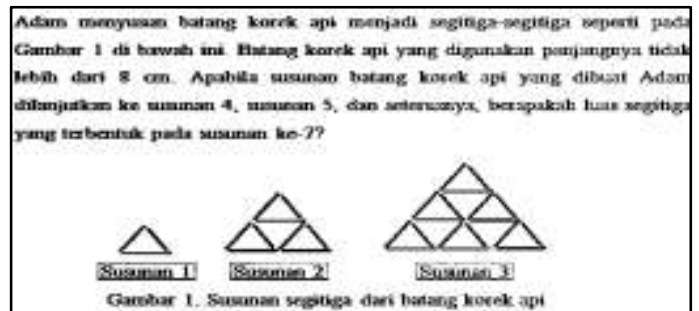

Data analysis is done by transcribing the collected verbal data, examining all available data, data reduction, data exposure, and conclusions. This data analysis is the main objective of the study, aiming to describe the students' mathematical communication process with guardian, artist, rational, and idealist personality types related to symbolic communication, logical communication, and verbal communication. This analysis is done each step by using the polya problem-solving step.

\section{Result and Discussion:-}

Based on the results of the questionnaire of the personality type given to 31 students in VIII-A class, it was obtained the data presented in the following chart.

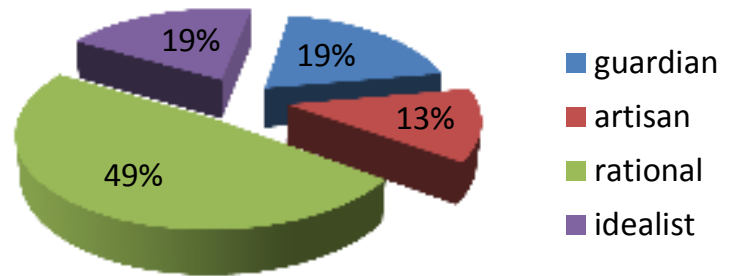

Figure 1:- Students' Personality Type Data of VIII-A Class

After the classification of personality types, then 1 student was selected from each personality type that became the subject of research. The chosen subject solved the open geometry problems based on Polya step which then analyzed the mathematical communication process based on the result of written work and interview. Here is the description of the students' mathematical communication process with guardian, artist, rational, and idealist personality type in solving the problems given in accordance with the stages of Polya problem solving.

\section{The Guardian Student's Mathematical Communication Process (SG) in Solving Open Geometry Problems}
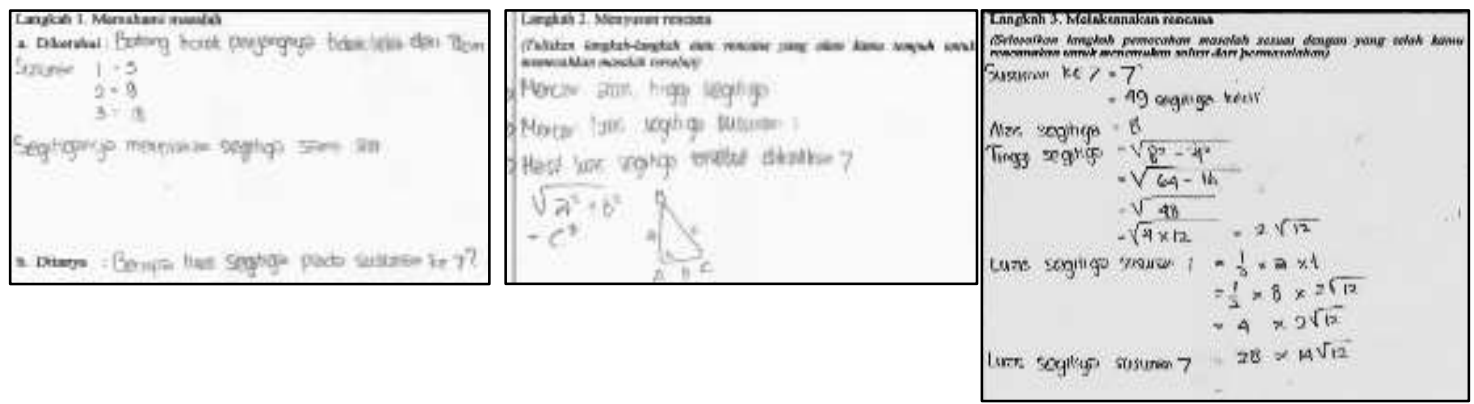


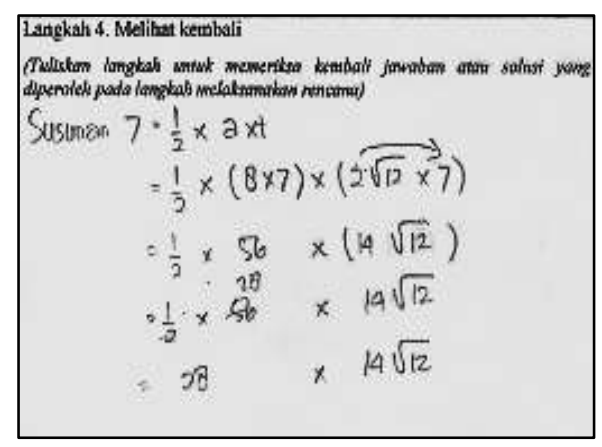

Figure 2:- Review of Answers from Guardian Subject (SG)

At the stage of understanding the problem, SG wrote the information known and asked the question correctly. The written information was the result of the observation of the given image. The symbolic communication from SG was using symbols of order $1=3$ and so on to state the number of matches in each arrangement. While verbal communication, it was known from the conclusion that the information known was enough to solve the problem. However, SG wrote unnecessary information about the number of triangle constituent lighters. This indicated that SG did not understand about the question. In addition, SG concluded that the triangle formed was an equilateral triangle because it had measured the side of the triangle with a ruler. SG made conclusions based on actual activities. This is in accordance with the opinion of Keirsey and Bates (in Panjaitan, 2015: 20) which describes a guardian likes to talk about concrete things or something that can be clearly observed.

At the drafting stage of the plan, SG can not adequately describe the problem-solving plan and its reasons clearly and logically. Symbolic communication indicated was that SG could write the rule of phytagoras formula, by giving side of right triangle with $\mathrm{a}, \mathrm{b}$, and $\mathrm{c}$ (c side as triangle side). While verbal communication, it was known from the conclusion that there was data that is not needed, that is the number of matches. SG concluded that the plans that had been prepared could be done by utilizing information that is known from the problem, although the reasons proposed by SG was not appropriate and not based on the results of reasoning.

At the stage of implementing the plan, the first step of the SG is to determine the number of triangles as in the 1st order contained in the 7th arrangement. However, SG revealed that the move was not from the results of his own thinking. In the next step, SG performed in accordance with the arranged plan. SG could describe clearly and there was a little error calculation in obtaining the final answer that was when multiplying the area of triangle in order 1 with 7. Thus, the logical communication of SG could be quite good. Symbolic communication owned by SG is that he could use triangle area formula and give the size of the triangle base precisely according to the condition given in problem. While verbal communication, it could be known that SG could not conclude steps done whether they were correct or not. SG was still unsure of the answers obtained because from the beginning SG did not understand what was asked from the problem. SG always remembered the problems met before. As what Keirsey and Bates (in Panjaitan, 2015: 20) say that a person with a guardian type usually prefers to follow the routine proceduree. He / she has gained from previous material relating to the material given at this time.

In the rechecking stage, during the interview, SG reviewed the steps chosen clearly and logically by checking the final answer in a different way. There was no miscalculation made by SG. His symbolic communication is that he can use the equilateral triangle formula correctly and understand the symbol a for the base of the 7 th order of the order which is 7 times long the length of a match, and the symbol t for the height of the 7th order triangle. While verbal communication, it is not shown because SG could not make conclusions about the truth of the final answer obtained. 


\section{Mathematical Communication Process of Artisan Student (SA) in Solving Open Geometry Problems}
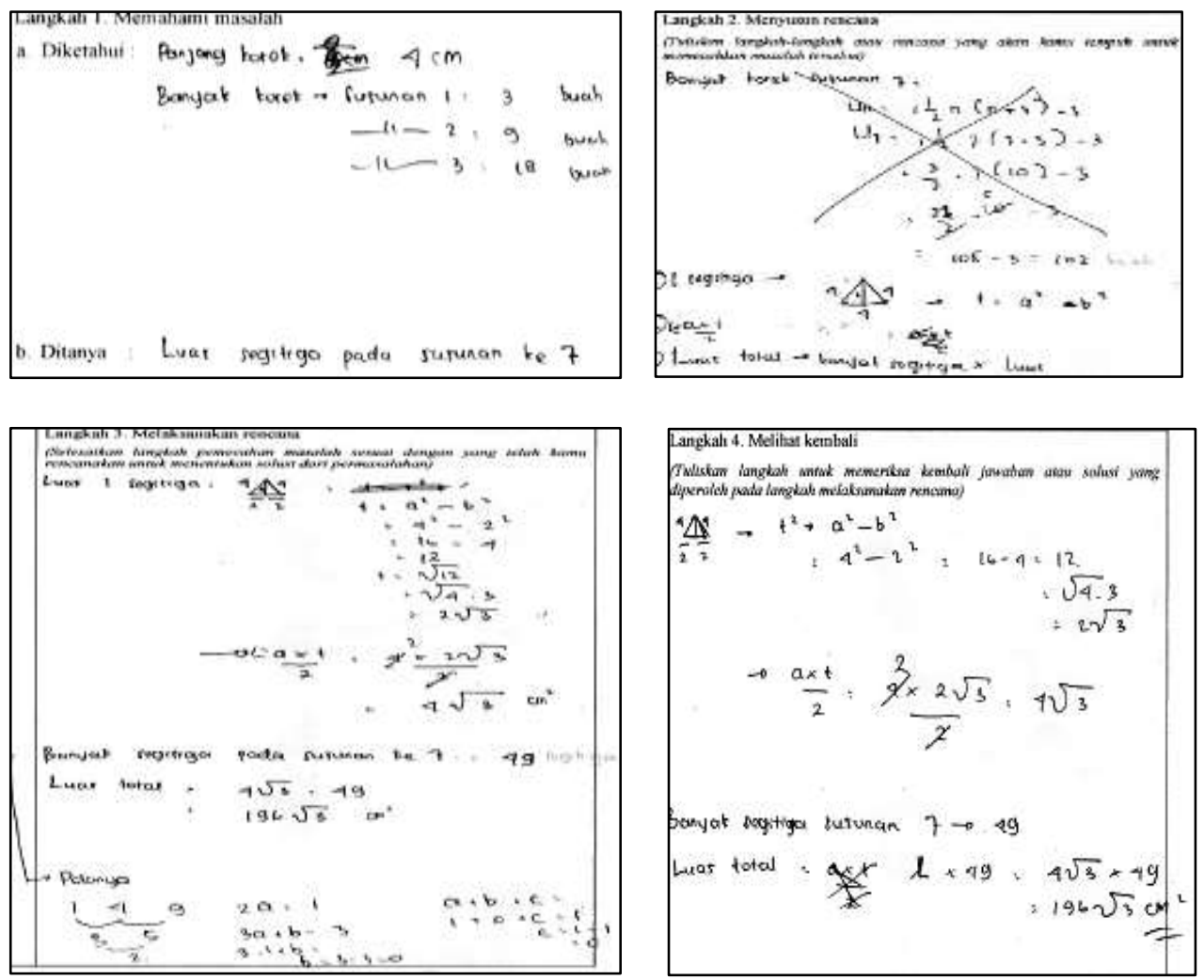

Figure 3:- Review Answers from the Artisan Subject (SA)

The artisan subject (SA) in solving the problem, at the stage of understanding the problem, logical communication and symbolic communiquency were shown by writing down the information known correctly and in accordance with the given image. SA directly described a match length is $4 \mathrm{~cm}$. As Keirsey and Bates (in Panjaitan, 2015: 20) have expressed, the artist type likes to talk about concrete things. SA understands what is being asked in the problem even though SA initially felt confused. Verbal communication was shown from SA's conclusions about unnecessary information in solving the problem, that is, the number of matches in each arrangement, and SA added another required information such as many triangles like the 1st arrangement that builds up in the 2 nd and 3rd order.

At the planning stage, SA showed less logical communication because they did not clearly describe the steps to be taken. SA just wrote down the rules used to solve the problem. This was more related to the symbolic communication. The phytagoras formula was written incorrectly, but SA understood the symbol used, ie $\mathrm{t}$ as the height of the triangle, a as the oblique side, and $\mathrm{b}$ as the half-sided side of the triangle. While the formula of the written triangle is correct. Verbal communication was known from the conclusion that the first step used was not appropriate, so SA replaced it with another step. This happened because the artist type tends to be too hasty and wants something done immediately to allow him to use any way that he thinks can be done immediately.

At the stage of implementing the plan, SA used the previous written rules in sequence. This showed the symbolic communication that SA had. In addition, SA replaced symbols with values corresponding to the information known to the problem. There was no miscalculation in getting the final answer. However he did not give a good reason to declare many triangles in the 7th order so that it could be said that his logical communication was still low. While verbal communication, it was indicated by concluding that the steps performed were correct and did not need to use different ways. As seen in the rechecking stage, SA still used the same steps.

In the rechecking stage, SA revealed that he did not just copy the previous work, but actually repeated the step from the beginning to check the truth of the results obtained. SA outlined the steps taken clearly and logically. Symbolic communication shown by SA was still low. One of them is SA did not write clearly the symbol for the height of the 
triangle, using the symbol t 2 or t. While verbal communication, SA concluded that the answer obtained was correct because it was equal to the answer in the previous step.

\section{Mathematical Communication Process of Rational Students (SR) in Solving Open Geometric Problems}

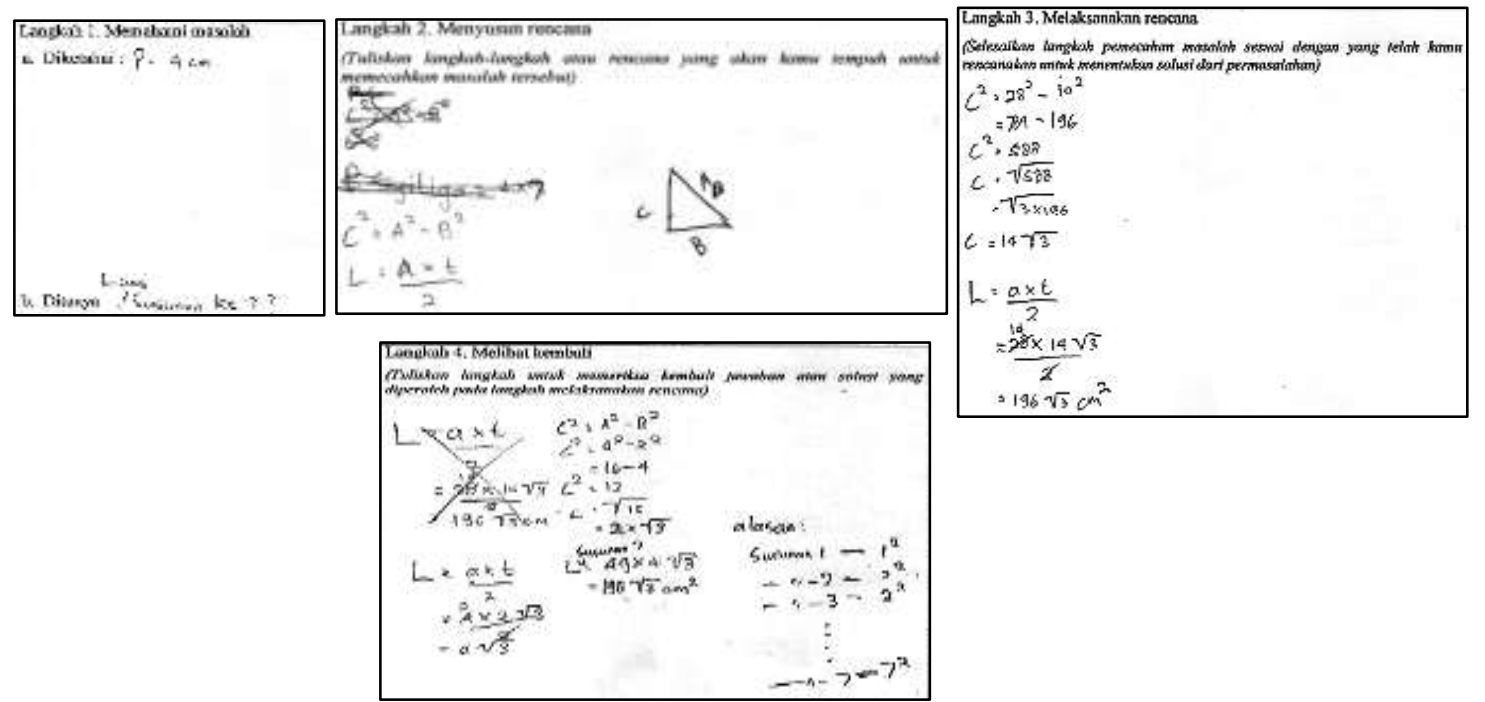

Figure 4:- Review Answers from Rational Subjects (SR)

At the stage of understanding the problem, SR wrote the information known correctly in accordance with the requirements in the problem, and mentioned what was asked correctly, so it could be said that the logical communication of SR is good. Symbolic communication was indicated by using the p symbol to denote the length of the match and the length is $4 \mathrm{~cm}$. While verbal communication, it was known from the conclusion that the information known is not enough to solve the problem. He must determine the height of the triangle to be able to determine the area of the triangle.

At the planning stage, SR did not write down the problem solving plan but only wrote the formulas to be used ie phytagoras formula and triangle area. SR described a right triangle to explain the sides referred to the phytagoras formula. It showed the symbolic communication of SR. Logical communication was shown orally when traced through interviews, SR could clearly describe the problem-solving plan and its reasons. Verbal communication was shown by SR's conclusion that he could use the information known to determine the other elements needed to solve the problem, while the element was not known in the question yet.

At the stage of implementing the plan, SR logical communication was demonstrated by solving the problem in accordance with the plan that had been prepared and created no errors of calculation performed. Based on the interview, SR could describe the steps or calculations clearly and be based on the results of reasoning. For example about the length of the base of the triangle obtained from the way SR explored the relationship between the arrangement of triangles presented in the problem. It is easy for someone with a rational type, because the rational type likes experiments and discoveries through exploration (Keirsey and Bates in Panjaitan, 2015: 20). Symbolic communication was demonstrated by using phytagoras formula and area of triangle correctly and could replace symbols in formulas with corresponding values. Verbal communication was known from the conclusion of SR that he believed the steps were done correctly because the formula used was correct and the answers obtained was in accordance with the request questions.

At the re-checking stage, SR checked whether the answers obtained were the same although they resolved it in different ways. SR described the steps taken clearly and logically and SR reused his reasoning by exploring the relationships between triangular arrangements to express the number of triangles such as the 1st arrangement of each arrangement 1, 2, and 3. Symbolic communication was shown by using phytagoras and broad formulas triangle correctly. In addition, SR used the symbols of arrangements 1 - 12 and so on to express the number of triangles that make up the triangles in the order of 1, 2, and 3. Meanwhile the verbal communication was shown from the SR 
conclusion that the final result obtained was correct after the checking step. SR solved the problem smoothly and there was no doubt in him.

\section{Mathematical Communication Process of Idealist Students (SI) in Solving Open Geometry Problems}

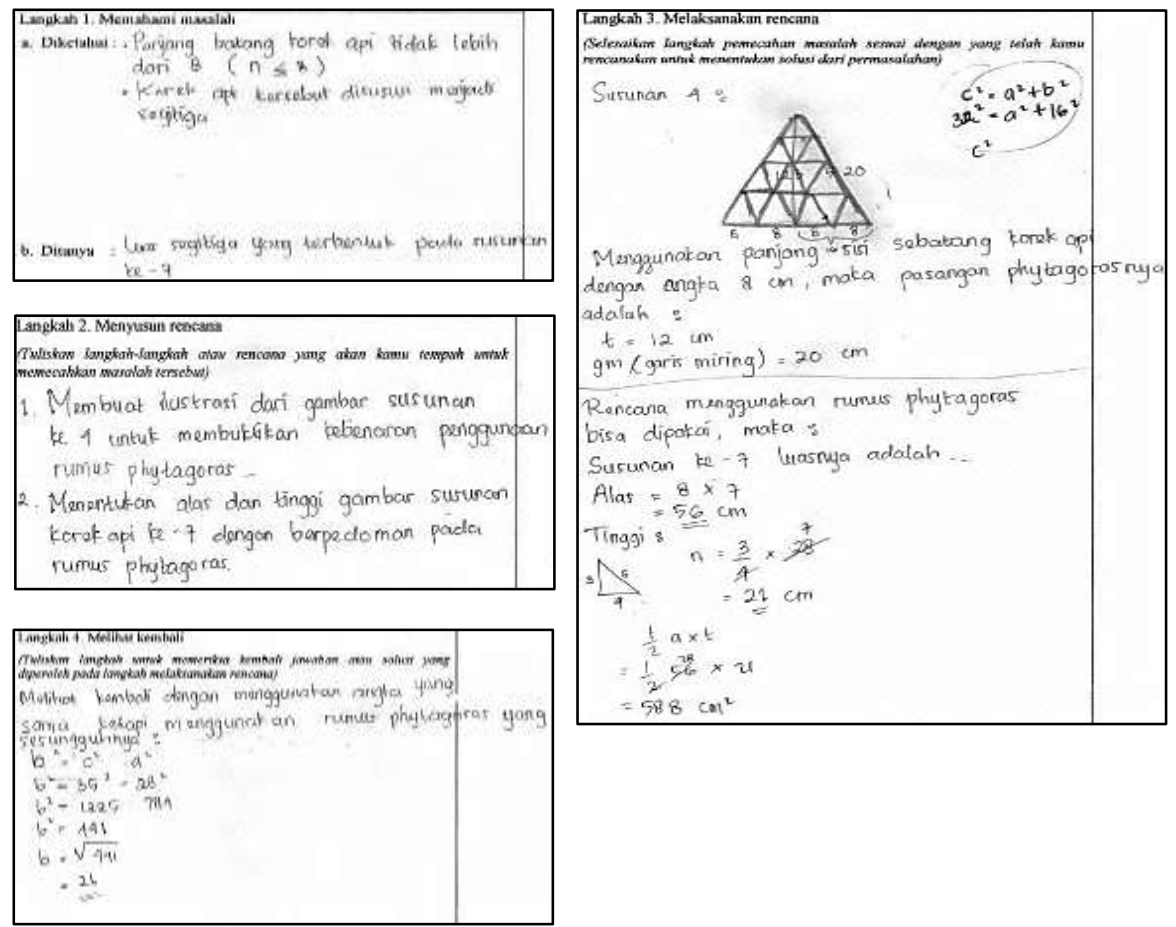

Figure 5:- Review Answers from the Idealist Subject (SI)

At the stage of understanding the problem, SI could write down the information known and asked clearly and correctly. Based on the interview, SI added another information that was the triangle which was formed on each arrangement was an equilateral triangle because the number of matchsticks was the same on each side and the length of the matches used has to be the same. The reasoning presented by SI showed that he could see images from different angles from other subjects. This is in accordance with the opinion of Keirsey and Bates (in Panjaitan, 2015: 20) that idealist type can see things with different angles. Symbolic communication was indicated by the use of $n \leq 8$ symbol to state the length requirement of the matchstick. Meanwhile verbal communication was shown from the conclusion that the information known was not enough to solve the problem because it still had to be determined the length of matches which was used as the size of the base of the triangle, then also had to be determined about the height of triangle.

At the stage of drafting the plan, SI outlined the problem-solving plan clearly but inappropriately. SI put forward his idea to solve the problem that it could be done by using phytagoras formula and the area of triangle or by Heron formula. However SI used only for the first step. As what Keirsey and Bates (in Panjaitan, 2015: 20) have expressed, an idealist prefers to communicate about his ideas and thoughts, as seen in SI. When preparing the plan, SI did not show the symbolic communication. While verbal communication was known from the conclusion that he could use all the data known but still doubt about the steps to be used.

At the stage of implementing the plan, SI solved the problem according to the plan that had been prepared. SI described the steps clearly and there was no error in the calculation. Thus, logical communication of SI could be said to be good, although the steps taken were not appropriate. Symbolic communication was shown by using the triangular area formula and specifying the length of matches correctly on the terms of the question. Meanwhile verbal communication was known from the conclusion that he could ensure the steps taken were not appropriate. Then, SI could explain the more appropriate step. 
In the rechecking stage, SI could provide an explanation of the steps taken to check the truth of the height of the triangle that had been obtained by using phytagoras formula and the size of the side as well as the side edge of the triangle. Based on the explanation above, logical communication of SI in checking back could be said good. Symbolic communication was shown by writing down and understanding the phytagoras formula correctly. While verbal communication, it was shown by making the conclusion that the results obtained by SI was not appropriate because it started from the selection of inappropriate problem solving strategy. This is in line with the results of Panjaitan's research (2015) which says that idealistic students do less mature planning so that after stepping there is a mistake. However, in the end, the student can immediately realize his mistake.

\section{Conclusion:-}

Based on the research that has been done, it can be concluded that students with guardian personality type in understanding the problem can show logical and symbolic communication, but they are less able to show verbal communication. In the planning step, it can show symbolic and verbal communication, but it is less able to show logical communication. In the step of implementing the plan, they are able to show symbolic and logical communication so well, but they are less able to show verbal communication. In the re-checking step, it can show logical and symbolic communication, but it is less able to show verbal communication. Characteristics which were seen in guardian students in solving problems are the students make conclusions based on concrete things or something that can be observed significantly, and they more follow the routine procedures that they ever had previously.

Artisan students in understanding problems can show logical, symbolic, and verbal communication. In the planning step, it can show symbolic and verbal communication, but it is less able to show logical communication. In the step of implementing the plan, it is able to show symbolic and verbal communication, but less able to show logical communication. In the checking step, it can show logical and verbal communication, but it is less able to show symbolic communication. Characteristics seen in artisan students in solving problems are to talk about the concrete, and tend to be in a hurry and want something done immediately so that it use any way he thinks can be done immediately.

Rational students in understanding problems, planning, executing plans, and re-examining can demonstrate logical, symbolic, and verbal communication. Characteristics seen in rational students in solving problems is that students can find a thing through exploration activities.

The idealist student in understanding the problem can demonstrate logical, symbolic, and verbal communication. In the planning step, it can show logical and verbal communication, but it can show less symbolic communication. In the step of implementing and rechecking the plan, it is able to show logical, symbolic, and verbal communication. The characteristic seen in idealistic students in solving problems is that students communicate their ideas and thoughts more. In planning, they are less mature, so that after stepping there are still errors. However, the student can immediately realize his mistake.

\section{References:-}

1. Armiati. 2009. Komunikasi Matematis dan Kecerdasan Emosional. Prosiding Seminar Nasional Matematika dan Pendidikan Matematika Jurusan Pendidikan Matematika FMIPA UNY hal 270 - 280.

2. Bents, R. 2010. Personality Type and Communication. www.flowinternational.eu. [4 Juni 2017].

3. Dewiyani, M. J. 2010. Menanamkan Pendidikan Karakter Berbasis Perbedaan Tipe Kepribadian pada Mata Kuliah Matriks dan Transformasi Linear di Stikom Surabaya. EDUMATICA Journal Pendidikan Matematika, $1(02)$.

4. Herman, Tantang. 2007. Pembelajaran Berbasis Masalah untuk Meningkatkan Kemampuan Berpikir Matematis Tingkat Tinggi Siswa Sekolah Menengah Pertama. Educationist No. 1 Vol. 1 Januari 2007 ISSN: $1907-8838$.

5. Keirsey, D. 1998. Please Understand Me II Character \& Temperament Types. California: Promentheus Nemesis Book Company.

6. National Council of Teachers of Mathematics. 2000. Principles and Standards for School Mathematics. Reston, VA: National Council of Teachers of Mathematics.

7. Panjaitan, Binur. 2015. Karakteristik Metakognisi Siswa dalam Memecahkan Masalah Matematika Berdasarkan Tipe Kepribadian. Jurnal Ilmu Pendidikan, Jilid 21, No. 1, Juni 2015, Hal 19 - 28. 
8. Polya, G. 1985. How To Solve It $2^{\text {nd }}$. New Jersey: Prence University Press.

9. Qohar, Abdul. 2011. Mathematical Communnication: What and How to Develop It in Mathematics Learning?. Proceeding International Seminar and The Fourth National Conference on Mathematics Education 2011 ISBN 978-979-16353-7-0.

10. The Literacy and Numeracy Secretariat. 2010. Communication in The Mathematics Classroom. Capasity Building Series special edition 13. 